\title{
Which Earnings Groups Have Been Most Affected by the COVID-19 Crisis?
}

\author{
Aaron Amburgey, Research Associate
}

Serdar Birinci, Economist

T he COVID-19 crisis has had unprecedented negative effects on the aggregate U.S. economy, but especially on the labor market. The unemployment rate jumped from 3.5 percent to 14.7 percent between February and April and only slightly decreased to 13.3 percent in May. Fifty million initial unemployment insurance (UI) claims have been filed so far this year, which is about 10 million more than total initial UI claims filed during the Great Recession. Besides its aggregate effects on the labor market, the COVID-19 crisis has had disproportionate effects on certain individuals. In this essay, we explore the differential labor market impacts across the earnings distribution.

When the pandemic caused unemployment to skyrocket, the lowest earners were the hardest hit.

To study these impacts, we first group occupations into quintiles based on the average annual earnings of individuals in each line of work. ${ }^{1}$ Table 1 displays the earnings ranges and examples of occupations in each quintile. Quintile 1 is dominated by service-industry occupations; quintile 2 and

quintile 3 are both mostly a mix of manual and office workers; quintile 4 is mostly technical occupations; and quintile 5 is mostly a mix of executive and various professional occupations in the law, medical, and financial fields.

Next, we calculate the change in total unemployed workers from January to April that belong to occupations in each earnings quintile. Table 2 displays the contribution that occupations in each quintile had to the total increase in unemployment and temporary layoffs between January and April. Values are calculated by taking the change in unemployed persons for those in a given quintile and dividing by the total change in unemployed persons across all quintiles. Each value tells us what proportion of the total increase in unemployment came from workers in occupations that belong to a given quintile. Notably, occupations in the bottom quintile accounted for 34 percent of the total increase in unemployment, while those in the top two quintiles only accounted for a total of 17 percent. There is no significant difference in these outcomes when we analyze only temporary layoffs. This finding provides evidence that the majority of the jobs being destroyedor at least furloughed-by the COVID-19 crisis are in occupations with lower earnings.

Table 1

Occupations by Earnings Quintile

(1)

$(<\$ 34,963)$

\begin{tabular}{cc}
$(<\mathbf{3 4 , 9 6 3 )}$ & $(\mathbf{\$ 3 4 , 9 6 3 - \$ 4 8 , 2 9 3 )}$ \\
\hline Cooks & Medical assistants \\
\hline Servers & Security guards \\
\hline Janitors & Clerks \\
\hline House cleaners & Construction workers \\
\hline Cashiers & Customer service reps
\end{tabular}

(3)

$(\$ 48,293-\$ 60,165)$

(4)

$(\$ 60,165-\$ 83,807)$

1st-8th Grade teachers

Retail salespersons

Maintenance/repair workers

Postal service workers

Retail supervisors/managers

Registered nurses

Industrial mechanics

Paralegals

Computer support specialists

Accountants/auditors
(5)

(>\$83,807)

Chief executives

Doctors/dentists

Financial managers

Lawyers/judges

Sales representatives

SOURCE: 2019-20 Current Population Survey, which is sponsored jointly by the U.S. Census Bureau and the U.S. Bureau of Labor Statistics, is the primary source of labor force statistics for the U.S. population. 
Table 2

Contributions to Unemployment Change by Occupation Earnings Quintile

\begin{tabular}{lccccc} 
& \multicolumn{5}{c}{ Quintile } \\
\cline { 2 - 5 } & $(1)$ & $(2)$ & $(3)$ & (4) & 11.38 \\
\hline All unemployed (percent) & 34.40 & 25.38 & 23.24 & 5.60 \\
\hline Temporary layoff (percent) & 35.29 & 24.82 & 22.77 & 11.69 & 5.43
\end{tabular}

SOURCE: 2019-20 Current Population Survey.

Table 3

Unemployment Rate by Occupation Earnings Quintile

\begin{tabular}{lrrrrr} 
& \multicolumn{5}{c}{ Quintile } \\
\cline { 2 - 6 } & $(1)$ & $(2)$ & $(3)$ & $(4)$ & 2.80 \\
\hline January (percent) & 5.62 & 4.40 & 13.52 & 2.23 & 7.42 \\
\hline April (percent) & 26.02 & 17.80 & 10.73 & 5.18 & 5.19 \\
\hline Change (percentage points) & 20.40 & 13.40 & 3.16
\end{tabular}

SOURCE: 2019-20 Current Population Survey. The last row presents the percentage point change in the unemployment rate between January and April.

Finally, as shown in Table 3, we calculate the unemployment rate in January and April for workers in each occupation earnings quintile as well as the change in the unemployment rate over this period. For example, workers in occupations in quintile 2 experienced an unemployment rate of 4.4 percent in January and 17.8 percent in April, a change of 13.4 percentage points. The unemployment rate in January was relatively low for each quintile, but particularly for quintiles 3, 4, and 5. In April it was extremely high for quintiles 1,2, and 3, while for quintiles 4 and 5 it was more moderate. Although the unemployment rate increased significantly in each quintile, the lower quintiles experienced far greater increases. These results provide further evidence that the COVID-19 crisis has had an unbalanced effect on different earnings groups in the labor market.
In conclusion, workers in occupations with lower average earnings were disproportionally displaced by the COVID-19 crisis, while workers in occupations with higher average earnings-especially those in the top 20 percent-were impacted to a lesser extent: From January to April, the unemployment rate increased to 5.34 percent for individuals in occupations at the highest average earnings level; it increased fivefold-to 26 percent-for those in the lowest average earnings level.

\section{Note}

1 We start with the set of occupations in the data and divide the occupations into earnings quintiles, taking into account the occupation employment shares. The earnings ranges for the quintiles are given in Table 1. For example, quintile 2 has the earnings range $\$ 34,963-\$ 48,293$. 